\title{
DESIGN AND EVALUATION OF TRANSDERMAL FILMS CONTAINING KETOPROFEN FOR THE TREATMENT OF ARTHRITIS
}

\author{
*Manjula $\mathrm{D}^{\mathbf{1}}$, Shabaraya $\mathrm{AR}^{2}$, Srikanth $\mathrm{P}^{3}$, Su ma $\mathrm{R}^{1}$ \\ ${ }^{1}$ Day ananda Sagar College of Pharmacy, Bangalore, Karnataka, India \\ ${ }^{2}$ Sriniv as College of Pharmacy, Mangalore, Karnataka, India \\ ${ }^{3}$ V.L. College of Pharmacy, Raichur, Karnataka, India \\ *Corresponding author's E-mail: manjulad21@ rediffmail.com
}

Received 28 May 2012; Review Completed 29 June 2012; Accepted 11 July 2012, Available online 15 July 2012

\begin{abstract}
ABS TRACT:
Transdermal drug delivery systems of ketoprofen have been formulated using solvent casting method. matrix type transdermal systems were prepared by using Hydroxy propyl methyl cellulose (HPMC) and ethyl cellulose (EC) polymers by incorporation glycerin and dibutyl phthalate as plasticizers respectively. Drug polymer interactions were studied by FT-IR and differential scanning calorimetry which showed no interaction between drug and the poly mers used. All the patches were uniform with respect to physico-chemical evaluation. The drug uniformity in the patch was observed by scanning electron microscopy which showed uniform distribution of drug throughout the patch. The in vitro drug release studies indicated that HPMC and EC patches with no permeation enhancer released the drug in an optimum rate. The various permeation parameters such as flux, permeability co-efficient, enhancement ration and diffusion rate constants were determined for all the formulations. The effect of permeation enhancer on the diffusion of ketoprofen across rat skin was determined. The maximu m flux of $9.52 \times 10^{-2} \mathrm{mg} / \mathrm{cm}^{2} / \mathrm{hr}$ was observed with HPMC monolithic sy stem containing 5\% v/v d-limonene. A significant improvement of flux was observed with 5\% d-limonene than that of $20 \%$ oleic acid. The in vitro release studies revealed that the release was sustained upto $24 \mathrm{hr}$ and followed zero order kinetics. Keywords: Ketoprofen, HPMC, EC, d-limonene and Oleic acid.
\end{abstract}

\section{INTRODUCTION:}

Arthritis is a major syndrome affecting majority of the geriatric patients and generally NSAID'S are advised to reduce pain and inflammation ${ }^{1}$. The medications prescribed for the relief of inflammation and associated pain are available as conventional dosages like tablets and capsules. The conventional medications cause GI disturbances and drug level fluctuates considerable making the patient to suffer or the patient is burdened with overdosage $^{2}$. To minimize the GI disturbances and to improve the bioavailability of the drug certain novel dosage forms are being investigated. In the past two decades there has been a commendable growth both in size and to improve bioavailability and patient compliance. Transdermal drug delivery systems (TDDS) are designed to support the passage of drug substances from the surface of skin, through its various layers, into the systemic circulation. Their advantages over conventional dosage forms include improved patient compliance, avoidance of gastric irritation and first-pass effect and controlled therapeutic responses ${ }^{3}$. Ketoprofen, a non-steroidal anti-inflammatory drug, used in the treatment of arthritis, can be used as a suitable model to develop TDDS because of its short halflife of about 2-3 hr and gastro-intestinal side effects ${ }^{4}$.

\section{MATERIALS AND METHODS :}

Ketoprofen was gift sample Themis laboratories Mumbai, HPMC and EC were gift samples from Ajanta Pharmaceuticals Mumbai, d-limonene, oleic acid were obtained from sd-fine chemicals. All the other reagents used were of analytical grade. HPMC and EC are hydrophilic and hydrophobic polymers respectively, to see their effect on release of ketoprofen through skin, so both the polymers are chosen for the present study.

\section{Drug polymer interaction by FT-IR ${ }^{5,6}$ :}

To investigate any possible interaction between the drug and the utilized polymer, IR spectrum of pure drug and its physical mixture was carried out by using FT-IR (Perkin elmer 1600 series USA) the range selected was from $400 \mathrm{c} \mathrm{m}^{-1}$ to $4000 \mathrm{c} \mathrm{m}^{-1}$.

\section{Preparation of monolithic trans dermal systems:}

Monolithic transdermal systems of HPMC and EC were prepared by solvent casting method on mercury surface as per mundane et al method ${ }^{7}$. Various formulations with their codes is tabulated in table 1. Poly meric solution was prepared by dissolving the respective polymer in combination of solvents, stirred on magnetic stirrer for 20 min with simultaneous addition of gylcerine and dibutyl phthalate as plasticizers for HPMC and EC patches respectively. Specific quantity of drug was dissolved in alcohol and added to the polymeric solution. Finally the resulting solution was poured within a glass bangle of $5 \mathrm{~cm}$ diameter placed on mercury surface in a petridish. The rate of evaporation of the solvent was controlled by inverting cut funnel over the petridish. After $24 \mathrm{hr}$ the dried patches were taken out and stored in a desiccator. The drug polymer ratio was 1:4 respectively and was kept constant for all the formulations. Various formulations prepared are depicted in table 1 . 
Table 1: Formu lation Codes of Various Monolithic Transdermal Patches Containing Ketoprofen

\begin{tabular}{|c|c|c|c|c|c|c|c|}
\hline \multirow{2}{*}{ S.No. } & Ingredients $(\mathrm{mg} / \mathrm{ml})$ & \multicolumn{5}{|c|}{ Formulation codes } \\
\cline { 3 - 8 } & & $\mathrm{F} 1$ & $\mathrm{~F} 2$ & $\mathrm{~F} 3$ & $\mathrm{~F} 4$ & F5 & F6 \\
\hline 1 & Ketoprofen & 50 & 50 & 50 & 50 & 50 & 50 \\
\hline 2 & HPMC & 200 & 200 & 200 & - & - & - \\
\hline 3 & EC & - & - & - & 200 & 200 & 200 \\
\hline 4 & Dibutyl phthalate & - & - & - & 0.0575 & 0.0575 & 0.0575 \\
\hline 5 & Glycerine & 0.0585 & 0.0585 & 0.0585 & - & - & - \\
\hline 6 & d-limonene & - & 0.0029 & - & - & 0.0029 & - \\
\hline 7 & Oleic acid & - & - & 0.0111 & - & - & 0.0111 \\
\hline 8 & Alcohol & 2 & 2 & 2 & 2 & 2 & 2 \\
\hline 9 & Dich loromethane & 1 & 1 & 1 & 1 & 1 & 1 \\
\hline 10 & Chloroform & 2 & 2 & 2 & 2 & 2 & 2 \\
\hline
\end{tabular}

\section{Methodol ogy:}

Physical appearance, weight and Thickness uniformity:

All the transdermal patches were visually inspected for color, clarity, flexibility and smoothness. The dried patches were weighed on afcoset digital balance. The average of five observations was taken. The thickness ${ }^{8}$ was measured by a screw gauge (mitutoyo Japan) at five different random points on the patch. The average of five observations was taken.

Table 2: Physical parameters of the transdermal systems

\begin{tabular}{|c|c|c|c|c|}
\hline S.No. & Formulation codes & Physical appearance & Weight (mg) & Thickness (mm) \\
\hline 1 & F1 & ++ & $272.2(0.49)$ & $0.167(0.0067)$ \\
\hline 2 & F2 & ++ & $275.1(0.32)$ & $0.147(0.0044)$ \\
\hline 3 & F3 & ++ & $279.5(0.35)$ & $0.129(0.0022)$ \\
\hline 4 & F4 & ++ & $291.7(0.42)$ & $0.149(0.0044)$ \\
\hline 5 & F5 & ++ & $315.1(0.34)$ & $0.149(0.0102)$ \\
\hline 6 & F6 & ++ & $325(0.44)$ & $0.167(0.0067)$ \\
\hline
\end{tabular}

\section{Water vapor transmission studies $(\text { WVT })^{9}$ :}

Glass vials of equal diameter were used as transmission cells. These cells were washed and dried in an oven. About $1 \mathrm{gm}$ of fused calcium chloride was taken in the cells and patch of area equivalent to brim of vial $\left(1.36 \mathrm{~cm}^{2}\right)$ was fixed with the help of an adhesive. The cells were weighed accurately and kept in a close desiccator containing saturated solution of potassium bromide $(200 \mathrm{ml})$. The humidity inside the desiccator was measured by a hygrometer and it was found to be $84 \% \mathrm{RH}$. The cells were taken out and weighed after 1, 2, 3, 4, 5, 6 and 7 days of storage. The WVT was calculated by taking the difference in the weight of the patches before and at regular intervals of $24 \mathrm{hr}$ for a total period of seven days.

Table 3: Data for water vapor transmission studies for monolithic systems.

\begin{tabular}{|c|c|c|c|c|c|c|c|c|c|}
\hline \multirow{2}{*}{ S.No. } & \multirow{2}{*}{$\begin{array}{c}\text { Formulation } \\
\text { codes }\end{array}$} & \multicolumn{7}{|c|}{ Cu mulative a mount of water vapour trans mitted in $\mathrm{g}$ ms } & \multirow{2}{*}{$\begin{array}{c}\text { WVT rate } \\
\text { constant } \\
(\mathrm{gm} / 24 \mathrm{hr} / \mathrm{sq})\end{array}$} \\
\hline & & $1^{\text {st }}$ day & $2^{\text {nd }}$ day & $3^{\text {rd }}$ day & $4^{\text {th }}$ day & $5^{\text {th }}$ day & $6^{\text {th }}$ day & $7^{\text {th }}$ day & \\
\hline 1 & F1 & 0.045 & 0.089 & 0.133 & 0.177 & 0.221 & 0.264 & 0.307 & $3.307 \times 10^{-2}$ \\
\hline 2 & $\mathrm{~F} 2$ & 0.050 & 0.105 & 0.157 & 0.209 & 0.26 & 0.311 & 0.384 & $4.137 \times 10^{-2}$ \\
\hline 3 & F3 & 0.049 & 0.099 & 0.147 & 0.195 & 0.243 & 0.291 & 0.362 & $3.900 \times 10^{-2}$ \\
\hline 4 & $\mathrm{~F} 4$ & 0.034 & 0.069 & 0.097 & 0.139 & 0.176 & 0.211 & 0.245 & $2.600 \times 10^{-2}$ \\
\hline 5 & F5 & 0.038 & 0.076 & 0.113 & 0.15 & 0.188 & 0.225 & 0.262 & $2.820 \times 10^{-2}$ \\
\hline 6 & F6 & 0.036 & 0.072 & 0.107 & 0.142 & 0.174 & 0.231 & 0.248 & $2.671 \times 10^{-2}$ \\
\hline
\end{tabular}

\section{Drug content uni for mity ${ }^{10}$ :}

Transdermal films of 1 sq.cm area was cut into small piece and transferred into $100 \mathrm{ml}$ volumetric flask. $25 \mathrm{ml}$ of methanol was added and shaken for $4 \mathrm{hr}$ to extract the drug. Finally, suitable dilutions were made using phosphate buffer pH 7.4 and absorbance was measured at $258 \mathrm{~nm}$.

In vitro permeation across the rat abdominal skin:

Preparation of the skin ${ }^{11}$ :

(c) 2011, JDDT. All Rights Reserved
The swis s albino rats were sacrificed by decapituation. The fresh abdominal skin was excised from swiss albino rats weighing $170-190 \mathrm{gm}$. The abdominal skin of excised hairless rat skin was separated along the epidermal junction and was kept under a steam of $60{ }^{0} \mathrm{C}$ water for exactly 50 seconds. The heat-treated skin was cleared of its subcutaneous fatty substances and immediately kept in normal saline solution to flatten and smooth. This step maintains the integrity and viability of the skin. 


\section{Permeation studies:}

A vertically assembled Keshary-Chien 12 diffusion cell having downstream volume of $50 \mathrm{ml}$ was used. The above skin was mounted on the diffusion cell and receiver compartment was filled with $50 \mathrm{ml}$ phosphate buffer of $\mathrm{pH}$ 7.4 and the temperature was maintained at $37{ }^{0} \mathrm{C}$. The samples were withdrawn every hour (replaced with $1 \mathrm{ml}$ fresh buffer to maintain sink condition) and their concentrations were measured in UV-spectrophotometer at $254 \mathrm{~nm}$. The permeation studies were carried out upto $24 \mathrm{hr}$.

\section{RES ULTS AND DISCUSS ION}

Fig 1, 2 and 3 shows the IR spectra of pure drug ketoprofen and the physical mixture of ketoprofen with HPMC polymer and EC polymer. Due to replication of peaks in IR spectra of physical mixture (fig 2 and 3 ) as that of pure drug ketoprofen (fig 1) indicate their co mpatibility.

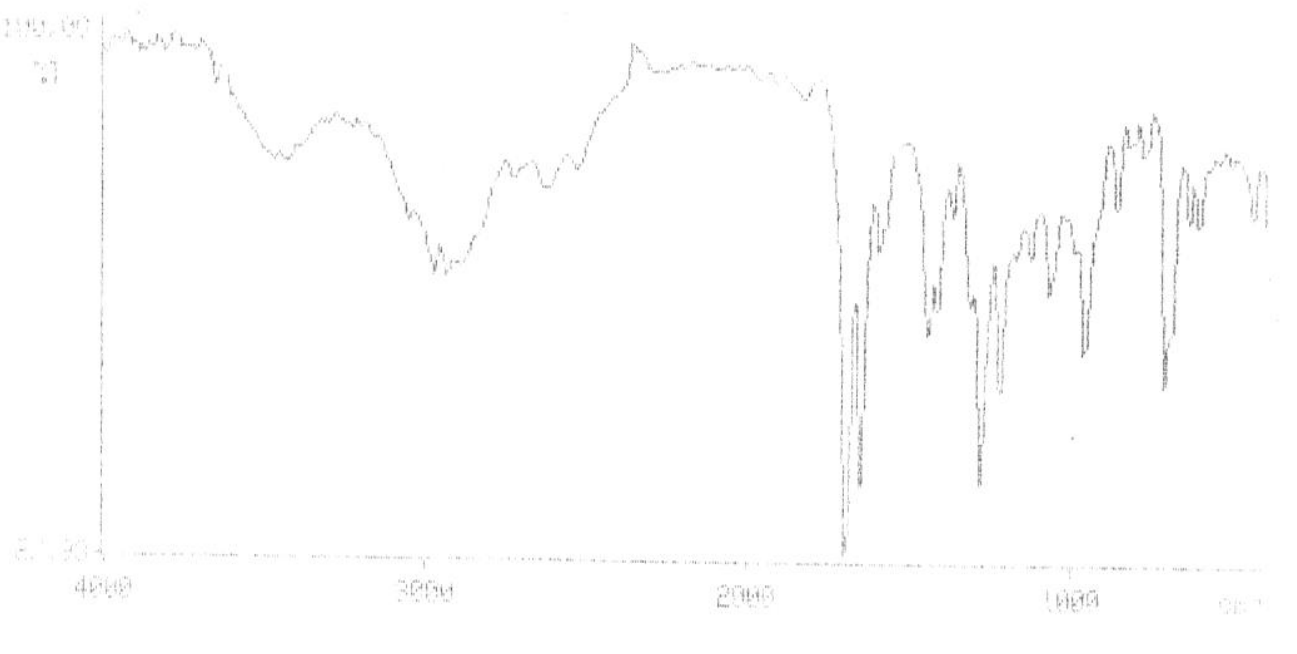

Figure 1: IR of Ketoprofen

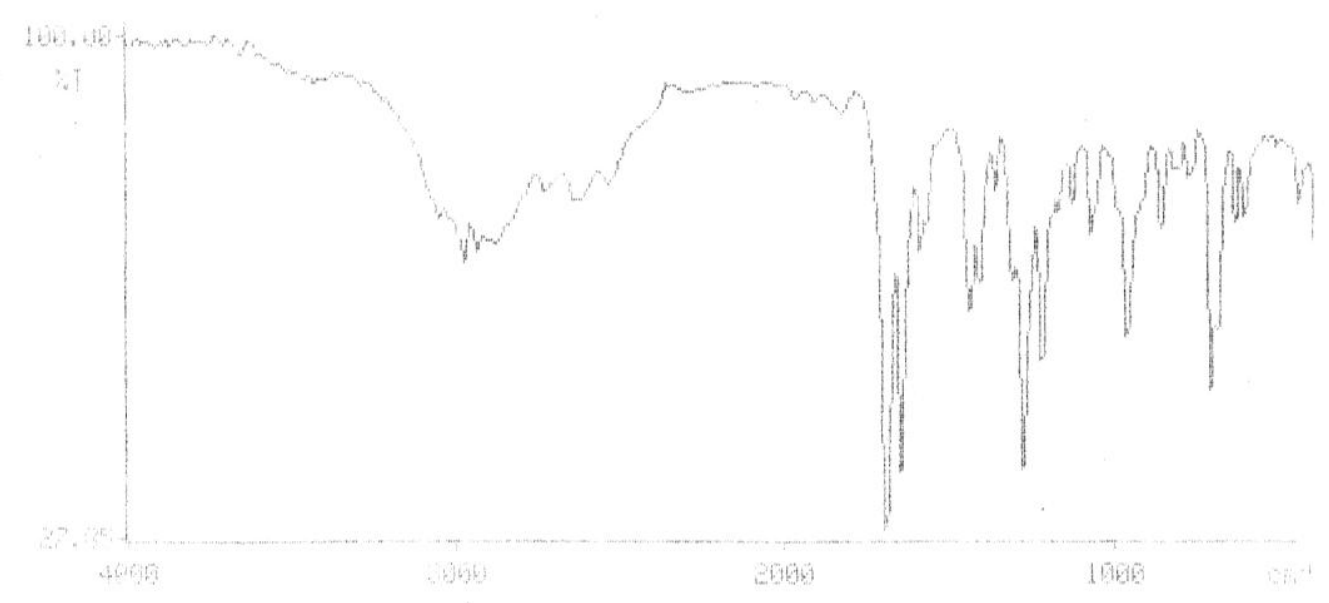

Figure 2: IR of ketopr ofen and HPMC mixture

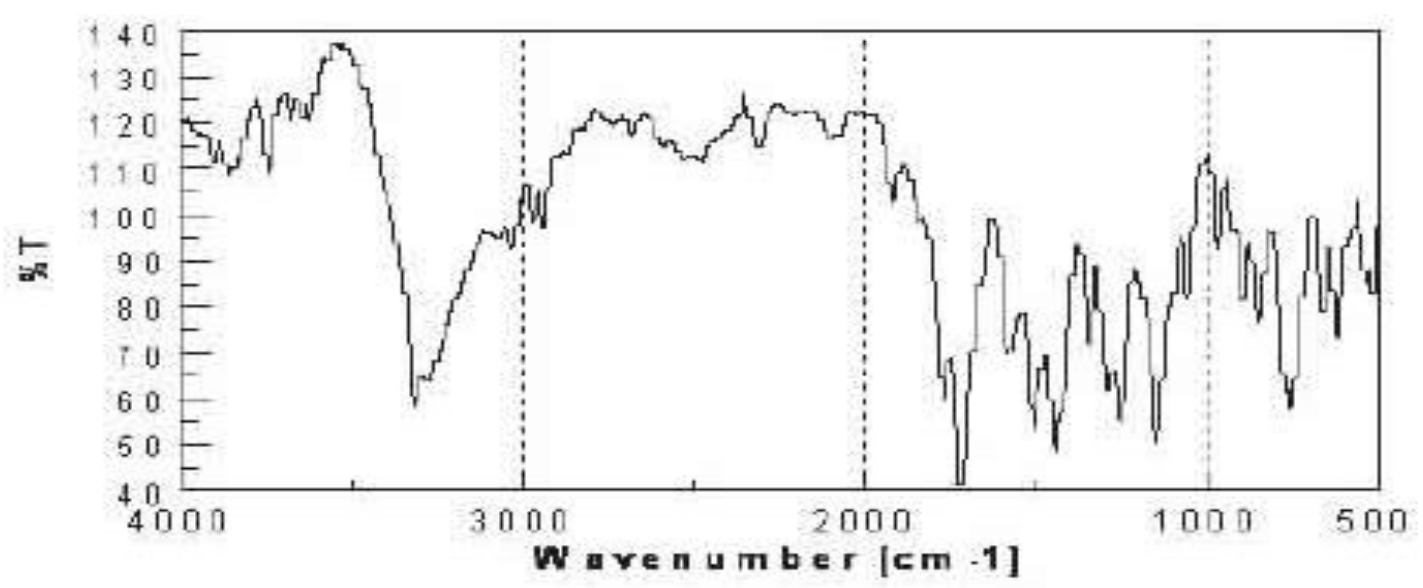

Figure 3: IR of ketopr ofen and EC 
In the next step, a total of 6 formu lations of monolithic and reservoirs were prepared using HPMC and EC poly mers as per formulae given in table 1 . All the films evaluated for their physical parameters were found to be flexible, smooth and transparent. They were also found to be uniform in their weight and thickness with low SD values as shown in table 2 .

The WVT studies (table 3) depicted that all the formulations from F1 to F6 were permeable to water vapour and among all the formulations HPMC containing patches showed good WVT than that of EC patches. The drug content was almost uniform in all the patches with low SD values (table 5).

The in vitro release of drug across rat skin from HPMC and EC showed only $57.66 \%$

( F1) and $43.11 \%$ (F4) at the end of $24^{\text {th }}$ hr respectively (Fig 4), the flux was calculated from the slope of linear graph and it was found to be $6.13 \times 10^{-2}$ and $4.59 \times 10^{-2}$ $\mathrm{mg} / \mathrm{cm}^{2} / \mathrm{hr}$, diffusion rate constants were 0.23 and 0.172 $\mathrm{mg} / \mathrm{hr} / \mathrm{cm}^{2}$ respectively (table 5 ). It was evident from the above result that there was a lower flux, poor drug permeability and less diffusion which might be attributed to tough barrier, stratum corneum of the skin; hence there was a need to incorporate permeation enhancer in the system. Two permeation enhancers namely d-limonene ${ }^{13}$ $(5 \% \mathrm{v} / \mathrm{v})$ and oleic acid $^{14}(20 \% \mathrm{v} / \mathrm{v})$ were incorporated and the drug release was studies. Among these systems, patch containing d-limonene in HPMC polymer (F2) showed maximu $\mathrm{m}$ release, whereas patch containing d-limonene in EC poly mer (F5) showed less release at the end of $24 \mathrm{hr}$. In the later study, $20 \%$ oleic acid was used as polymer in both HPMC (F3) and EC poly mer (F6) among which $20 \%$ ole ic acid in HPMC polymer showed more release. On the whole, HPMC polymer showed more release than oleic acid (Fig 5).

Table 4: Comparative kinetic values of drug release from trans dermal monolithic and reservoir systems.

\begin{tabular}{|c|c|c|c|c|c|}
\hline \multirow{2}{*}{ S.No. } & \multirow{2}{*}{ Formul ation codes } & \multicolumn{2}{|c|}{ Zero or der equation } & \multicolumn{2}{|c|}{ Higuc hi's equation } \\
\cline { 3 - 6 } & & $\mathrm{N}$ & $\mathrm{R}$ & $\mathrm{N}$ & $\mathrm{R}$ \\
\hline 1 & $\mathrm{~F} 1$ & 2.3323 & 0.9968 & 21.3516 & 0.9352 \\
\hline 2 & $\mathrm{~F} 2$ & 3.8781 & 0.895 & 20.6712 & 0.9375 \\
\hline 3 & F3 & 3.6614 & 0.9952 & 8.557 & 0.9517 \\
\hline 4 & F4 & 1.7153 & 0.9963 & 15.440 & 0.9546 \\
\hline 5 & F5 & 3.1247 & 0.9981 & 14.952 & 0.9477 \\
\hline 6 & F6 & 3.0186 & & & 0.9501 \\
\hline
\end{tabular}

Table 5: Permeability co-efficient, flux, enhancement ratio and diffusion rate constant of transdermal monolithic system

\begin{tabular}{|c|c|c|c|c|c|c|}
\hline S.No. & $\begin{array}{c}\text { Formulation } \\
\text { codes }\end{array}$ & $\begin{array}{c}\text { Permeability co- } \\
\text { efficient } \\
\mathbf{m g . m m} / \mathbf{h r}\end{array}$ & $\begin{array}{c}\text { Flux } \\
\mathbf{m g} / \mathbf{c m}^{\mathbf{2}} / \mathbf{h r}\end{array}$ & Drug Content & $\begin{array}{c}\text { Enhancement } \\
\text { ratio }\end{array}$ & $\begin{array}{c}\text { Diffusion rate } \\
\text { constant } \\
\mathbf{m g} / \mathbf{h r} / \mathbf{c m}^{\mathbf{2}}\end{array}$ \\
\hline 1 & F1 & $2.56 \times 10^{-2}$ & $6.13 \times 10^{-2}$ & $98.5(0.25)$ & - & 0.230 \\
\hline 2 & F2 & $4,001 \times 10^{-2}$ & $9.52 \times 10^{-2}$ & $99.1(0.35)$ & 1.55 & 0.358 \\
\hline 3 & F3 & $3.632 \times 10^{-2}$ & $8.68 \times 10^{-2}$ & $98.9(0.37)$ & 1.45 & 0.326 \\
\hline 4 & F4 & $1.927 \times 10^{-2}$ & $4.59 \times 10^{-2}$ & $97.2(0.27)$ & - & 0.173 \\
\hline 5 & F5 & $3.402 \times 10^{-2}$ & $8.10 \times 10^{-2}$ & $98.1(0.36)$ & 1.32 & 0.305 \\
\hline 6 & F6 & $3.326 \times 10^{-2}$ & $7.77 \times 10^{-2}$ & $97.8(0.41)$ & 1.26 & 0.292 \\
\hline
\end{tabular}

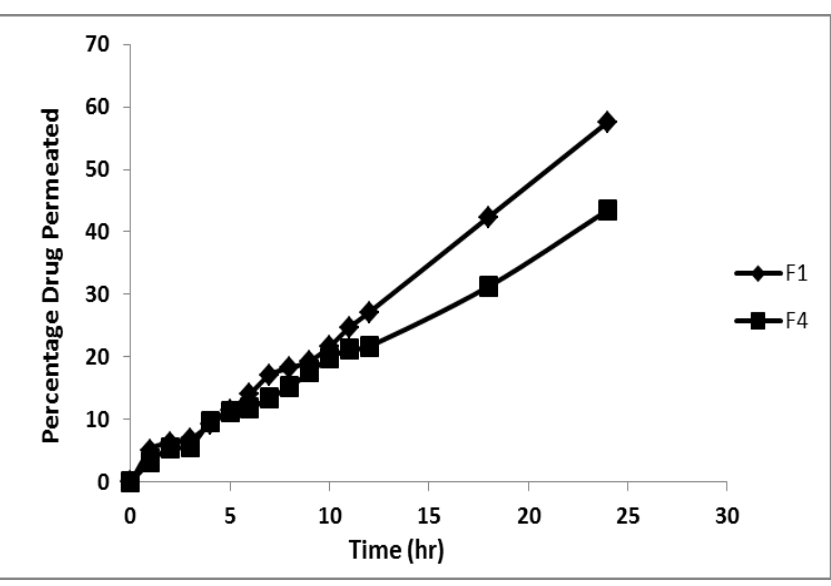

Figure 4: In Vitro Drug Release from Formulations F1 and $\mathbf{F} 2$ across Rat Abdominal Skin

(c) 2011, JDDT. All Rights Reserved

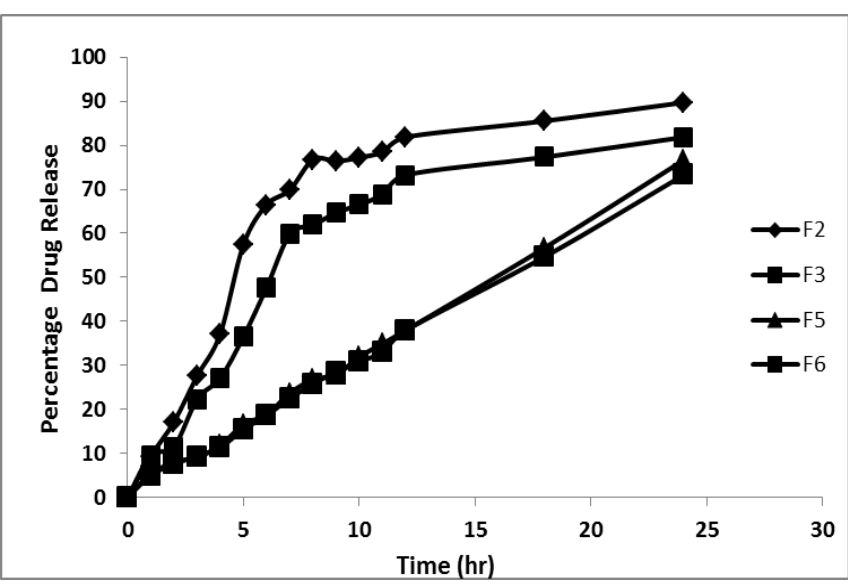

Figure 5: In Vitro Drug Release from Formulations F2, F3, F5 and F6 Across Rat Abdominal Skin

ISSN: 2250-1177 


\section{CONCLUSIONS:}

The fabricated polymeric films containing ketoprofen had shown uniform thickness, weight variation and drug content. In vitro skin permeation profile of the films was fairly uniform. Among two permeation enhancers $d$ limonene showed significant enhancement of drug permeation than oleic acid. The results of the study indicate the feasibility of formulating rate controlled transdermal therapeutic systems of ketoprofen for effective

\section{REFERENCES :}

1. Robert L Jackson, Marrow D Jason. Analgesic-antipyretic, anti-inflammatory agents and drugs used in the treatment of gout, $10^{\text {th }}$ Edn., Mcg raw Hill publication., New York, 2003.

2. Chien Yie W. Concepts and system design for rate controlled drug delivery, $2^{\text {nd }}$ Edn, Marcel Dekker Inc, 1992; 312-320.

3. Chien YW, In; Robinson, J.R and Lee, V.H.Controlled drug Delivery: Fundamentals and Applications, 2nd Edn., Marcel Dekker Inc., Newy ork, 1987; 523 - 524.

4. Shailesh KS, David SR, Indra KR, Manzer JD and Mansoor AK. Effect of additives on the diffusion of ketoprofen through human skin. Drug.Dev.Ind.Pharm. 1999; 22(9): 471-474.

5. Fregany A, Mohammed, Hussin Dhedr. Preparation and in vitrolin vivo evaluation of buccal adhesive properties of slow-release tablets containing miconazole nitrate. Drug Dev Ind Pharm. 2003; 29(3): 321-37.

6. Vandana G, Ashok KB, Suman R. Formulation development and in vitro characterization of proliposomes for topical delivery of aceclofenac. Ind.J.Pharma.Sci. 2008; 70(6): 768775 .

7. Loganathan V, Senthikumar B, Reddy MVS, Sreekanth N, Ubaidulla U. Compatibility studies between sparfloxacin and tablet excipients through differential scanning calorimetry. Int J Pharm Excip. 2003; 2(3,4), 661-64.

8. Mundane BL., Evaluation of polymeric materials and screening of film coating agent. J Pharma Sci. 1964; 53: 395. management of chronic pain, inflammation associated with rheumatoid and osteoarthritis conditions.

\section{ACKNOWLEDGEMENT:}

The authors are thankful to Vision group on science and technology for the grants provided to carryout this project and also thankful to management Dayananda Sagar College of Pharmacy, Bangalore, V.L.College of Pharmacy, Raichur.

9. Raghavendra K, Dodday y H, Marihar SC, Patil CC, Habbu PV. Comparative evaluation of polymeric films for transdermal application. The Eastern Pharmacist. 2000; XLIII (153): 109-111.

10. Gattani SG, Zawar LR, Kakade KN and Surana SJ. Optimization of transdermal films of lovastatin. Indian Drugs. 2008; 45(11): 883-889.

11. Kusum devi V, Saisivam S, Maria GR, Deepti PU. Design and evaluation of matrix diffusion controlled transdermal patches of verapamil hydrochloride. Drug Dev Ind Pharm. 2003: 29(5); 495-503.

12. Flynn GL, Durrheim H, Huguchi WI. Permeation through hairless mouse skin II: membrane sectioning techniques and influence on alkanol permeabilities. J Pharm Sci. 1981: 70(1): 52-56.

13. Chien YW. Systemic drug delivery of pharmacologically active molecule across the skin. Vol 100. New York.. 1991. 100-102.

14. Jaehwi Lee, Yoonjin Lee, Jongseok Kim, Mikyeong Yoon and Young Wook Choi. Formulation of microemulsion systems for transdermal delivery of aceclofenac. Arch.Pharm Res. 2005; 28(9): 1097-1101.

15. Gattani SG, Gaud RS and Chaturvedi SC. Formulation and evaluation of transdermal films of chlorpheniramine maleate. Indian Drugs. 2007; 44(1): 27-33. 